in particular circumstances show a preference for mating with other individuals, that is, show heterothallic behaviour. It is as though the individual possessed partially effective heterothally genes. In this way a balanced inbreeding-outbreeding system can be maintained.

It is also possible that such behaviour exists as a stage in the transit between full homothally and full heterothally. In Primula sinensis ${ }^{2}$ and Petunia sp. ${ }^{7}$ the efficiency of the key outbreeding genes is probably controlled by modifying polygenes. The main genes for heterostyly in the one case and for incompatibility in the other may then give either increased or decreased outbreeding by selection of the polygenic complex. Though not yet proved, it seems likely that selection could even reduce the efficiency of the outbreeding genes to zero, that is, completely to remove their power of affecting the breeding system. If this is so, it is easy to see that polygonic selection could lead to the gradual development of an adaptive breeding mechanism. The intermediates between homo- and heterothallic behaviour are susceptible to a similar interpretation and this could be tested by suitable selection experiments. The question of how $\mathbf{a}+$ and $\mathbf{a}-$ nucleus can occur in different parts of the same homothallic haploid then resolves itself, as, on this view of polygenic modification, the nuclei, though capable of developing heterothallic behaviour, will not inevitably possess a 'sex'.

Such a brief survey forbids the detailed mention of special cases, but it can be seen that the complications of hoterothally fit into an ordered scheme when viewed as adaptations to the control of outbreeding. Basically, the function and genetical structure of heterothally are the same as those of systems found elsewhere. The superficial differences are imposed by peculiar circumstances arising from the existence of an independent haploid phase.

${ }^{1}$ Mather, K., J. Genet., 41, 159 (1941).

${ }^{2}$ Mather, K., and de Winton, D., Ann. Bot., N.S. 5, 297 (1941).

suller, A. H. R., Bot. Rev., 7, 335 (1941).

- Riley, H. P., Genetic8, 21, 24 (1936).

s Newton, D. E., Ann. Bot., 40, 105 (1926).

${ }^{6}$ Huttig, W., Z. Bot., 24, 529 (1931).

"Mather, K., unpublished.

\section{HALLEY'S WORK AS A GEOGRAPHER}

$\mathrm{T}$ HE remarkable progress made in geography in the seventeenth and early eighteonth centuries owed much to a distinguished band of scholars at Oxford. This progress was made in two branches of the subject. On one hand, there was a large output of cosmographical works in which the authors, who were also teachers at Oxford, tried to present the rapidly growing geographical knowledge of the world. On the other hand, mathematicians developed that side of geography which was closely related to navigation. It was one of the duties of the Savilian professor of astronomy to deal particularly with this aspect of the subject, although in practice his colleague, the Savilian professor of geometry, seems to have been equally interested and active. Halley held the chair of geometry, and the more important part of his contribution to geography is attractively dealt with by Prof. S. Chapman in his paper "Edmund Halley as Physical Geographer and the Story of his Charts" (Occasional Notes, Roy. Astron. Soc., No. 9, June, 1941).

In addition to the work described by Prof. Chapman, Halley contributed some geographical papers to the Oxford Philosophical Society, made a survey of the tides of the English Channel, and undertook a journey to the Adriatic Sea. $\mathrm{He}$ is, however, best known for his charts, and with these Prof. Chapman deals fully, illustrating his paper by some excellent reproductions and by three isogonic charts of different periods. He also disposes of the claim that Halley explained correctly the physical causes of the trade winds.

At the end of his paper, Prof. Chapman refers to the geographical inaccuracies of Halley's charts. These, as he points out, were "due mainly to the necessity to estimate longitude". Soon after Halley's maps were published, the cartographical researches of $\mathrm{G}$. Delisle led to great improvements, while before he died John Harrison had invented the chronometer and so had made possible the accurate determination of longitude. Prof. Chapman also refers to certain "geographical curiosities" on Halley's maps, including the courses of certain rivers in Asia and Africa. It should be recalled that when Halley wrote there had been very little exploration of Asia and practically none of Africa. Geographers, in the case of the latter continent, had to rely largely on classical tradition and the work of Leo Africanus. How great was the ignorance and the fascination of the Dark Continent can be read in Defoe's story of the adventures of Captain Singleton.

Prof. Chapman's paper is timely in appearance, for the two hundredth anniversary of Halley's death is being commemorated this year. Halley held his Savilian chair until his death and did much to promote the study of applied geography. It is too much to say, as does the "Dictionary of National Biography", that he laid the foundation of physical gaography but, none the less, his work was substantial and of lasting value : to it Prof. Chapman does full justice.

J. N. L. BAKER.

\section{NOMENCLATURE OF $\mathrm{Cl}$. welchii 'TOXINS' TYPE $A$}

$\mathrm{T}$ $\mathrm{HE}$ investigation of the toxins produced by $\mathrm{Cl}$. welchii type $A$ (classic gas gangrene of man) has led to the recognition of the complex nature of the soluble substances recovered from filtrates of cultures of this organism. The attempt to analyse these substances into their component elements has led to certain unfortunate confusions in the nomenclature, as pointed out by Llewellyn-Smith .

[n view of the difficulties presented to research workers by this state of affairs, an informal meeting convened by Dr. M. Stephenson was held, under the chairmanship of Prof. T. Dalling of the Institute of Animal Pathology, Cambridge, at the Biochemical Laboratory in Cambridge on April 5, 1941, at which workers actively engaged in research in this field and those responsible for the production of antisera were present by invitation.

After a full discussion it was decided to adopt the following nomenclature as the basis for future publication.

(1) Among the antigenic substances found in filtrates the main toxic element is characterized by the following biological properties : 